\title{
Implementation of a New Concept of Conduct of the Electric Network Based on the Control of Topology
}

\author{
Mr. Najd BELAGUIDE ${ }^{1}$, Mr. Abdelaziz BELFQIH ${ }^{2}$, Mr. Abdellah SAAD ${ }^{3}$ \\ ${ }^{1,2,3}$ Energy and Power Systems Team, National Higher School of Electricity and Mechanics (ENSEM) \\ Hassan II Ain Chok University, PO Box 8118, Oasis, Casablanca, Morocco \\ E-mail:"najdos@hotmail.com,2a-belfqih@hotmail.com,3saad.abdal@gmail.com
}

\begin{abstract}
The conduct of the electrical networks has known in recent year's major changes induced mainly by the technological development of power electronics as well as the information systems and communication (Smart Grid), added to this is the integration of intermittent sources of production and competitive requirements advocating the power quality and the continuity of service as major objectives. That said it is understood that the electrical networks serve a set of vulnerabilities due to the intrinsic parameters including the" topology" of the network which requires the distribution of power that can migrate to unstable states face particular hazards. Before foregoing the present work is a participation in the development of a new concept of regulation of power systems based on the control of the topology provided to develop the network stability by a new field control which is not supported in patterns regulatory body.
\end{abstract}

Keywords: Load Flow, Smart Grid, FACTS.

\section{INTRODUCTION}

Regulating electric networks reflects a desire to remain in stable conditions of service of electrical installations while providing the necessary adjustments to adapt to the fluctuations of the electrical parameters of the network because of internal and external request.

This research fits as a continuation of the first phase $[1,2]$, which was allocated to study the impact of intrinsic parameters of the network and specially the reactance of electrical lines in all physical phenomena showing the vulnerability of networks provided to develop a new mode of regulation based on the control of the network topology in order to respond to any possible vulnerabilities [3].

\section{PROBLEMATIC \& OBJECTIVES}

As previously described the electrical network is facing a set of hazards [4] that affect its stability including:

\section{VOLTAGE COLLAPSE \\ FREQUENCY COLLAPSE \\ LOSS OF SYNCHRONISM \\ CASCADE OF OVERLOAD}

The inability to control physical parameters of the system may encourage the development of these hazards and degenerate to unstable conditions that could lead to BLACKOUT [5] [6]. The present work, and as illustrated in Figure 1, serves to develop a new approach of regulation to ensure the stability of the distribution of powers in different nodes of the network.

The approach lead to the optimization of the regulating means through a system enabling a change of the network topology as necessary. 


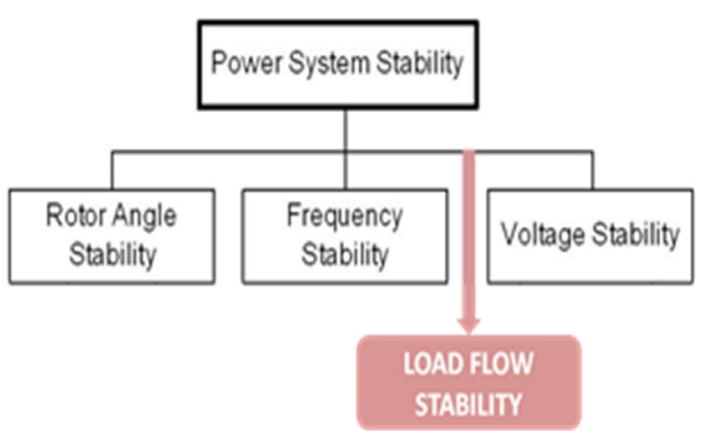

Fig. 1. Power System Stability

\section{STATEMENT OF THE APPROACH ADOPTED}

\subsection{Global View}

The calculation of load flow allows the determination of the electric state (current, voltage and power) at various nodes constituting the network. As illustrated in a simple case of Figure 2, the resolution of power assessments at each node allows to determine the complex voltages at each point and; thus, to infer the power flows in the network.

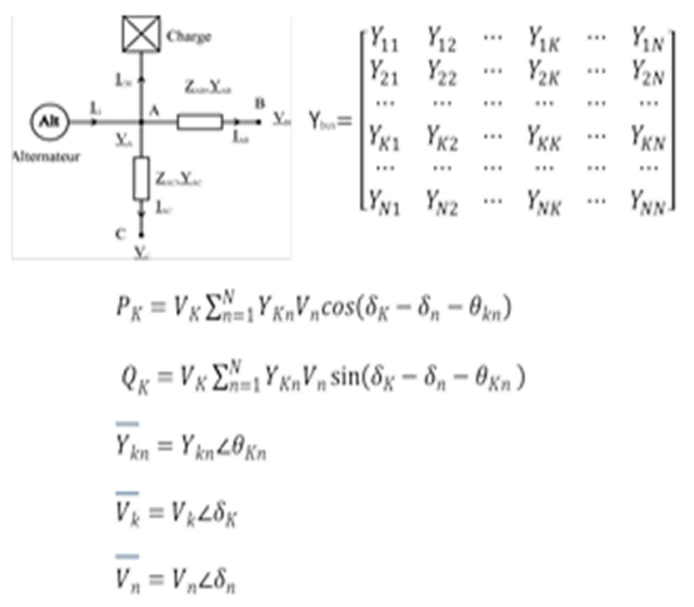

Figure 2: Load Flow

The principle of this concept is to migrate to a new mode of regulation of the electricity network coordinated by the addition of a device FACTS [7] [8] (Flexible AC Transmission Systems) in the arteries of power lines (figure 3 ) to act on the equivalent reactance. These FACTS will be ordered from a centralized processing centre (Dispatching) according to algorithms and converging towards the following objectives:

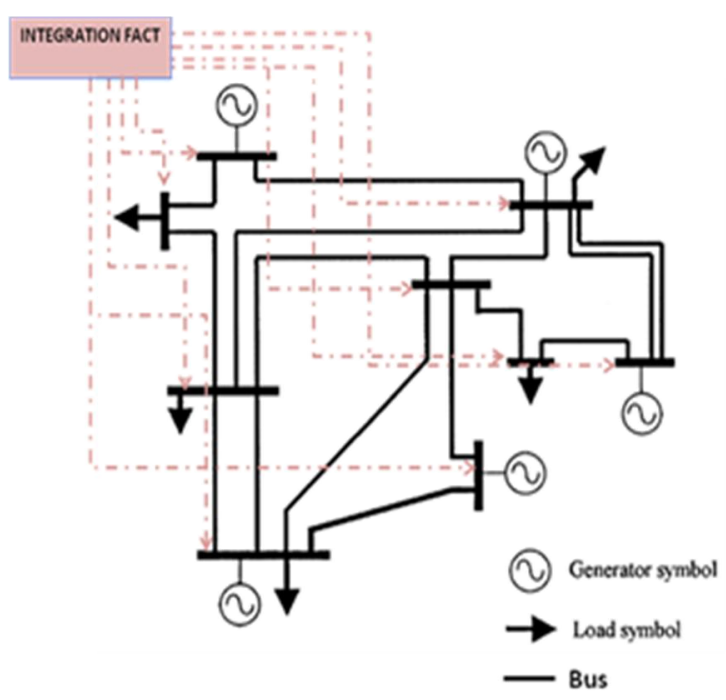

Figure 3: Integration of FACTS at the nodes of the electrical network

\subsection{Means of Integration of the Facts}

The integration of FACTS series at nodes of electrical networks as detailed in Figure 4 will be carried out by adding FACTS series at the busbar of transfer to allow a flexible control that can affect all the power lines leading to the main busbar and to optimize the operating cost and the modification of the structure of the items making up the network.

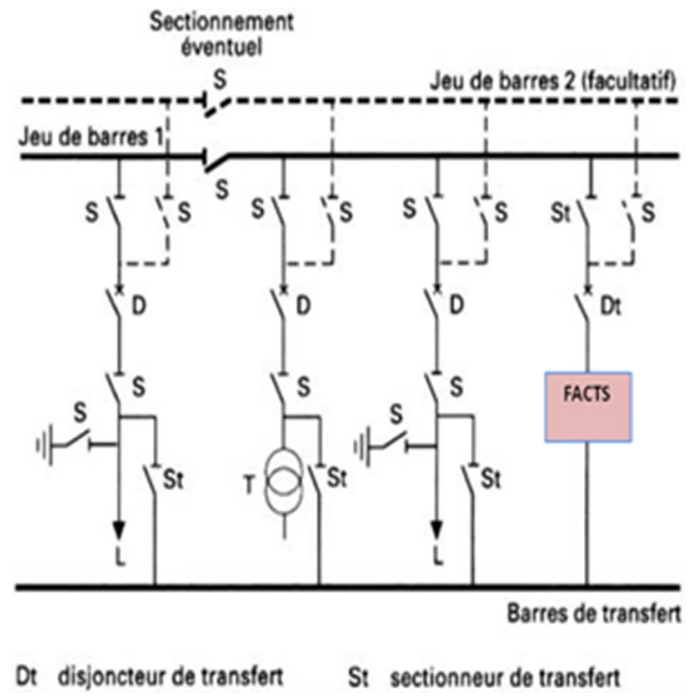

Fig. 4. Implementation of FACTS at a node of the electrical network 


\subsection{Control of Electrical Parameters}

The impact of the addition of FACTS on the performance of an electric line is demonstrated on several levels.

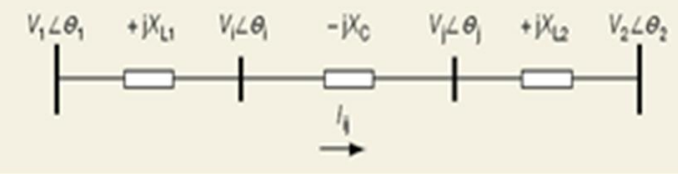

Fig. 5. Equivalent Model Addition Fact series on the electrical line

Through Figure 5, we can see that the equivalent reactance of the electrical line now depends certainly on the reactance of the line and also on the variation of the integrated TFACTST reactance.

This option provides flexibility order to control the intrinsic electrical parameters [9] [10] of the network as shown in Figures 6 and 7 and in the impact of the variation of the reactance of FACTS on the curves of power and voltage.

\section{Voltage variation}

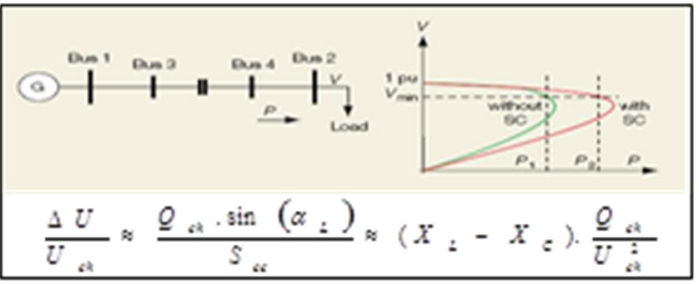

Fig. 6. Voltage variation

\section{Power variation}

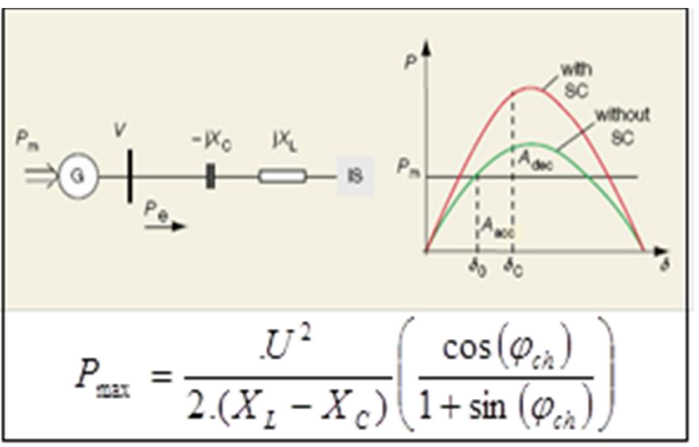

Fig. 7. Power variation

\section{Synthesis}

It was evident to us to see from our review of the literature $[11,12,13,14,15]$ that the development of solutions based on FACTS devices at electrical networks are limited to some network parameters but without integrating all the network parameters which are interdependent; therefore, our approach aims at a coordinated regulation answering at best the various compromises imposed by the electrical network.

\subsection{Coordinated Regulation of the Sharing of Power}

\subsubsection{Principle}

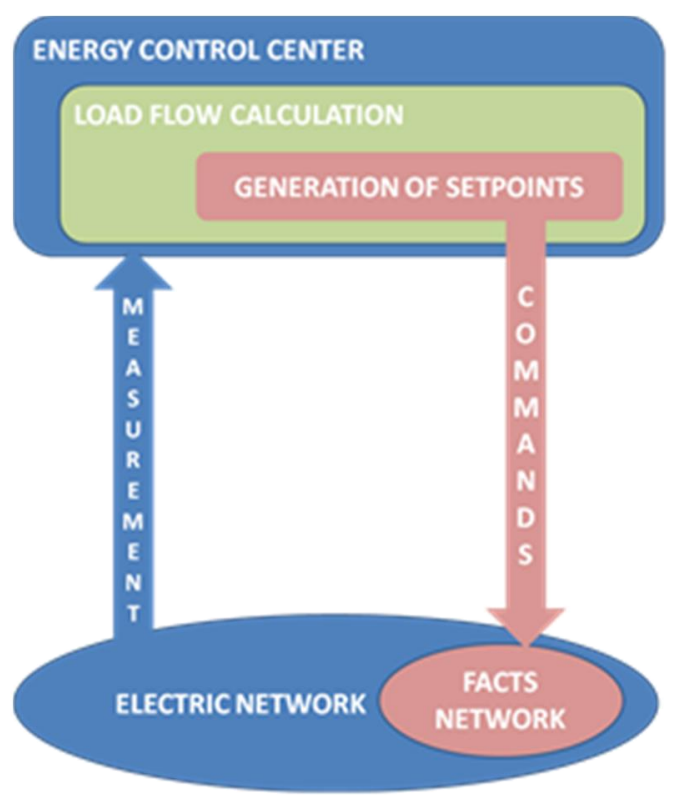

Fig. 8. Principal view

Figure 8 shows our expected goal that consists in adapting the distribution of power to the electrical network by controlling the FACTS devices integrated into the network and according to algorithms migrating to a stable operating states.

\subsubsection{Control of the distribution of loads}

We formulate the following equations between the nodal voltages and injected current for a 
network with $\mathrm{n}$ nodes:

$$
\begin{aligned}
I & =Y . V \\
I_{i} & =\sum_{j=1}^{n} Y_{i j} \cdot V_{j} \quad(i=1, \ldots . n)
\end{aligned}
$$

In practice, the system is known by the apparent power injected. The $\mathrm{n}$ complex equations are divided into $2 \mathrm{n}$ real equations:

$$
\begin{aligned}
& S_{i}=P_{i}+j Q_{i}=V_{i} \cdot I_{i}^{*} \\
& S_{i}^{*}=P_{i}-j Q_{i}=V_{i}^{*} \cdot \sum_{j=1}^{n} Y_{i j} \cdot V_{j} \\
& P_{i}=V_{i} \sum_{j=1}^{n} V_{j}\left(G_{i j} \cos \theta_{i j}+B_{i j} \sin \theta_{i j}\right) \\
& Q_{i}=V_{i} \sum_{i=1}^{n} V_{j}\left(G_{i j} \sin \theta_{i j}-B_{i j} \cos \theta_{i j}\right)
\end{aligned}
$$

And, by expressing the tension in Cartesian form:

$$
\begin{aligned}
& P_{i}=e_{i} \sum_{j=1}^{n}\left(G_{i j} e_{j}-B_{i j} f_{j}\right)+f_{i} \sum_{j=1}^{n}\left(G_{i j} f_{j}+B_{i j} e_{j}\right) \\
& Q_{i}=f_{i} \sum_{j=1}^{n}\left(G_{i j} e_{j}-B_{i j} f_{j}\right)-e_{i} \sum_{j=1}^{n}\left(G_{i j} f_{j}+B_{i j} e_{j}\right)
\end{aligned}
$$

With:

$V_{i}, \theta_{i}$ : the modulus and the phase of the voltage at node i

$P_{i}, Q_{i}$ : active and reactive power injected at node $\mathrm{i}$

$G_{i j}+j B_{i j}$ : the element $Y_{i j}$ of the complex matrix admittances

$\theta_{i j}=\theta_{i}-\theta_{j}$ : the phase difference between

nodes $\mathrm{i}$ and $\mathrm{j}$

$e_{i}, f_{i}:$ the real and imaginary parts of the voltage at node $\mathrm{i}$

\section{Synthesis}

The variation of complex elements of the admittance matrix allows us to control the active and reactive power at different nodes of the network as shown in below formulas:

$$
\begin{gathered}
\boldsymbol{P}_{i}=e_{i} \sum_{j=1}^{n}\left(\left(G_{i j}-G c_{i j}\right) e_{j}-\left(B_{i j}-B c_{i j}\right) f_{j}\right) \\
+f_{i} \sum_{j=1}^{n}\left(\left(G_{i j}-G c_{i j}\right) f_{j}+\left(B_{i j}-B c_{i j}\right) e_{j}\right) \\
\boldsymbol{Q} *_{i}=f_{i} \sum_{j=1}^{n}\left(\left(G_{i j}-G c_{i j}\right) e_{j}-\left(B_{i j}-B c_{i j}\right) f_{j}\right) \\
-e_{i} \sum_{j=1}^{n}\left(\left(G_{i j}-G c_{i j}\right) f_{j}+\left(B_{i j}-B c_{i j}\right) e_{j}\right)
\end{gathered}
$$

\subsubsection{Classification of the constraints}

The constraints related to the conduct of electrical networks define the limits of normal operation of the equipment in terms of dielectric strength and thermal operating limit and the maximum limit of transits and also the limits of stability that occur in terms of balance between production and consumption. We will list below the various constraints to be managed in the conduct of electrical networks.

\section{a. Constraints on balance between production and consumption:}

The equality between production and consumption directly impact the variation in frequency in the electrical generators network and provided to ensure the stability of the network frequency; these equations must be respected at all times:

$$
\begin{aligned}
& \sum_{\substack{i=1 \\
n g}}^{n g} P_{g i}-\sum_{i=1}^{n c} P_{c i}-P_{L}=0 \\
& \sum_{i=1}^{n c} Q_{g i}-\sum_{i=1}^{n} Q_{c i}-Q_{L}=0
\end{aligned}
$$

$P_{L}:$ total active loss

$Q_{L}$ : total reactive loss

$n_{c}$ : number of consumer nodes

$n_{g}:$ number of generation nodes

\section{b. Constraints on the voltage module:}

The voltage at the network is subject to continuous variations in view of the interdependence of the electrical parameters of the network. The operation of the network must ensure a range of variation according to the following limits: 
-The maximum voltages by dielectric strength of the material and transformer saturation.

-The minimum voltage by increasing losses and maintaining the stability of generators.

$V_{i}^{\min }<V<V_{i}^{\max }(\mathrm{i}=1, \ldots \ldots . \mathrm{n})$

with: $\quad V_{i}$ : the module voltage of the node $\mathrm{i}$

$V_{i}^{\text {min }}:$ Minimum limits

$V_{i}^{\max }:$ Maximum limits

\section{c. Constraints on transit capacity of the line:}

The maximum limit of transits of electricity formulated below must be respected at all times

$S_{i j}<S_{i j}^{\max }$ pou nu neligne $i-j$

With:

$S_{i j}=\left(P_{i j}^{2}+Q_{i j}^{2}\right)^{1 / 2}$

$S_{i j}$ : the apparent power transited

$S_{i j}^{\max }$ : the maximum apparent power transited

$P_{i j}$ : the active power transited

$Q_{i j}$ : the reactive power transited

The resulting consequences of any excess at the power transmitted can have negative results in a line that should, in no case, exceed the maximum limit.

\section{d. Constraints on production}

The power produced by each group is bounded above by the maximum power it can supply and below by the minimum, which is determined by the performance of the group and the constraints on the turbine. For all nodes in production, active and reactive constraints are:

$P_{i}^{g, \min } \leq P_{i}^{g} \leq P_{i}^{g, \max }$

$Q_{i}^{g, \min } \leq Q_{i}^{g} \leq Q_{i}^{g, \max }\left(\mathrm{i}=1, \ldots \ldots, n_{g}\right)$

\subsubsection{Flow Chart of the Algorithm of Coordinated Regulation}

State of normal operation I

-Triggering a network element (line, transformer, busbar).

-Variation of the load.

\section{Transition to a new topology J}

-Measurement of physical parameters of the new network

-Calculation of load flow.

-Identification of contraints

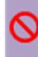

-Identification of the new network topology to overcome the constraints identified

-Identification of setpoints Facts for adapting the network topology

-Identification of the time constants associated with timers triggering protections fitted to the studied network

\section{Migration of the network topology to a new stable}

operating state " $\mathrm{K}$ "

Fig. 9. Flow chart of the control algorithm

\section{PRELIMINARY RESULTS}

\subsection{Network Study}

Our study was developed at the regional center of the $225 \mathrm{kV}$ transmission network of Morocco item of Figure 10.

the network consists of 24 nodes: 6 nodes generation, the others are loads nodes (the data used in this study are from the year 2012). 
Mr. N. Belaguide et al. / International Journal of Computer Networks and Communications Security, 1 (6), November 2013

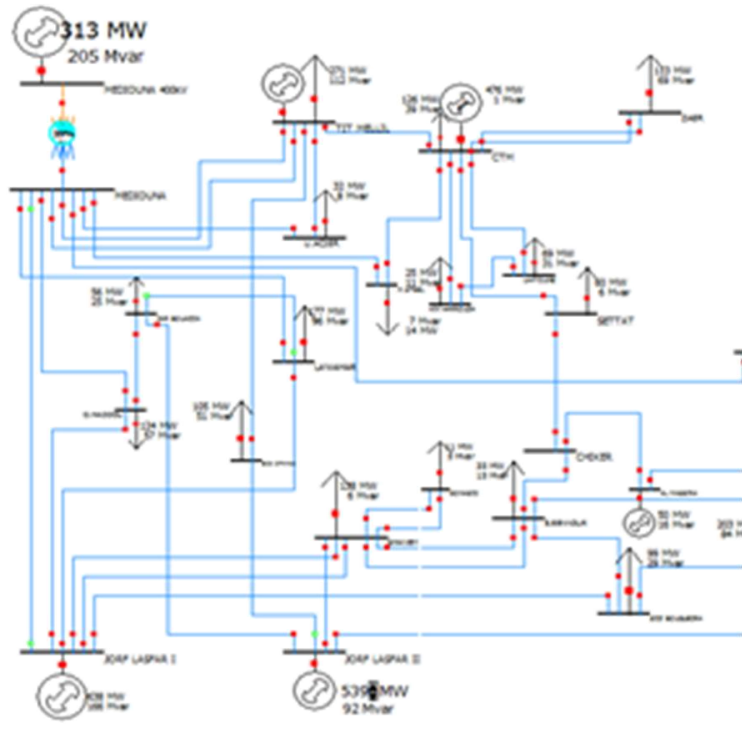

Fig. 10. Network studied

\subsection{Parametric Analysis of Network Studied}

Parametric analysis of the studied network has allowed us to identify areas of greatest vulnerabilities and which can escalate to blackout situation as illustrated at Figure 11 registered after successive trigger lines 22-8 and 22-19.

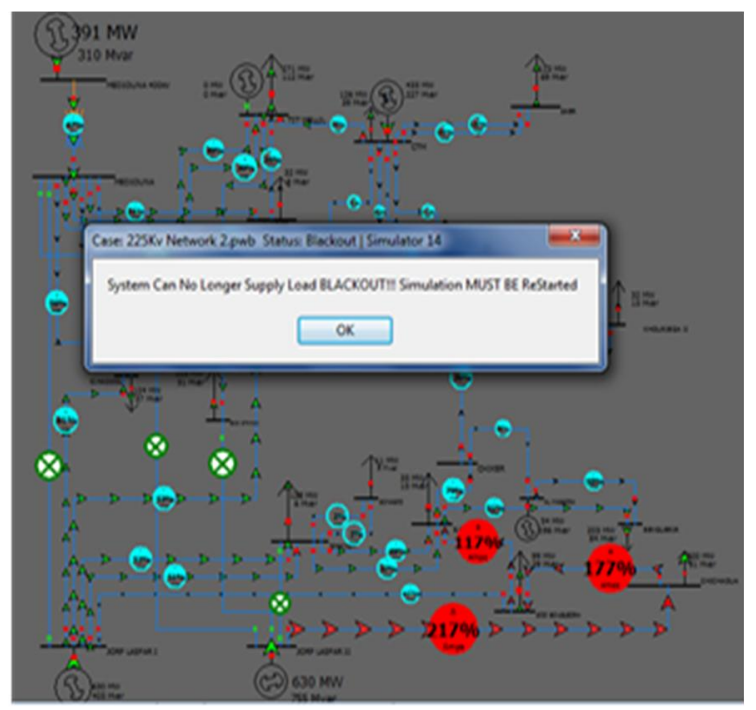

Fig. 11. parametric analysis of situation of-BLACKOUT-

\subsection{Impact Assessment of the Approach Adopted}

According to Chart flow described above, a program was primarily developed in MATLAB to calculate the load distribution using the NewtonRaphson method. The results are presented in Table 1.
Table 1: Results of POWER FLOW using MATLAB

\begin{tabular}{|c|c|c|c|c|c|c|c|c|}
\hline \multirow{3}{*}{$\begin{array}{l}\left|\begin{array}{l}30 \\
\mid\end{array}\right| \\
|300|\end{array}$} & \multirow{3}{*}{$\begin{array}{l}1 \\
1\end{array}$} & \multicolumn{7}{|c|}{ 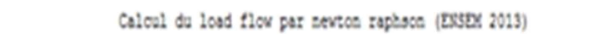 } \\
\hline & & i hesle & \multicolumn{2}{|c|}{ tsyectios } & \multicolumn{2}{|c|}{ Gesera:tes } & \multicolumn{2}{|r|}{$\cos$} \\
\hline & & I Desset & $x$ & xa: । & $y$ & mo: & $y z$ & | $x_{i n:}$ | \\
\hline$:$ & 2.0000 & 0.0000 & 199.198 & 242.498 & 199.1s! & 242.490 & 0.000 & 0.000 \\
\hline 2 & $\therefore .0042$ & -0.7571 & -259.200 & 256.669 & 28.000 & 369.169 & 271.100 & 212.100 \\
\hline 3 & 1.0000 & 0.2572 & $34 . .900$ & 196.069 & 474.005 & 234.569 & 125.500 & 34.500 \\
\hline 1 & 0.9904 & -2.5926 & -113.200 & -69.200 & 0.000 & 0.000 & 113.200 & 69.100 \\
\hline$s$ & 0.9996 & 0.1642 & -14.000 & -7.000 & 0.000 & -0.050 & 14.050 & 7.000 \\
\hline 6 & 0.999 & 0.1692 & -25.000 & -21.000 & 0.000 & 0.000 & 25.000 & 21.000 \\
\hline 9 & 0.9962 & 0.0985 & -68.600 & -30.600 & 0.000 & -0.000 & 68.650 & 30.600 \\
\hline 4 & 0.9293 & 4.0996 & -55.600 & -25.200 & 0.000 & -0.000 & 55.600 & 25.200 \\
\hline 9 & 0.8499 & $=0.0464$ & $-: 176.700$ & -96.400 & 0.000 & 0.000 & $: 976.700$ & 96.400 \\
\hline 20 & 0.9254 & 0.8992 & -60.000 & -6.900 & 0.000 & 0.000 & 60.000 & 6.900 \\
\hline :! & 0.994: & $-1.03: 9$ & -32.000 & $=: 5.400$ & 0.000 & -0.000 & 32.050 & 25.400 \\
\hline 12 & 0.9446 & 2.4775 & -124.450 & -57.405 & 0.000 & 0.000 & 124.400 & 57.400 \\
\hline 19 & 2.0009 & -1.6642 & $-: 05.200$ & -51.400 & 0.000 & 0.000 & 205.200 & 58.200 \\
\hline 14 & 0.8736 & 3.6224 & 0.000 & 0.000 & 0.000 & 0.000 & 0.000 & 0.000 \\
\hline 25 & 0.8648 & 3.5253 & $19.8 \times 0$ & 25.909 & 19.900 & 25.989 & 0.000 & 0.000 \\
\hline 16 & 0.8259 & 1.7127 & -202.700 & -41.600 & 0.005 & 0.000 & 202.700 & 83.600 \\
\hline$: 7$ & 0.8929 & 12.6924 & $\cdot: 0.580$ & -5.200 & 0.000 & 0.000 & 20.500 & 5.200 \\
\hline 18 & 0.8592 & 9.5107 & -35.380 & -14.900 & 0.000 & 0.000 & 35.900 & 14.500 \\
\hline 19 & 0.8993 & $12.671:$ & $-: 997.800$ & -5.500 & 0.000 & 0.000 & 197.800 & 5.500 \\
\hline 20 & 0.7449 & -4.940 & -100.280 & -51.100 & 0.000 & 0.000 & 309.200 & $\$ 1.100$ \\
\hline $2 !$ & 0.8169 & 3.4615 & .99 .380 & -29.100 & 0.000 & 0.000 & 9.900 & $29.1 \mathrm{~W}$ \\
\hline 22 & 0.9840 & 23.4610 & 600.080 & 171.937 & 660.005 & 171.937 & 0.000 & 0.000 \\
\hline 29 & 0.9899 & 25.65:3 & 660.000 & 87.620 & 660.000 & 87.620 & 0.000 & 0.000 \\
\hline 24 & 2.0028 & -0.6925 & -12.000 & -4.300 & 0.000 & $\rightarrow .000$ & 32.000 & 8.300 \\
\hline Tota! & & & 72.959 & $4: 2.694$ & 2060.959 & 2:20.994 & 2989.000 & $7: 7.700$ \\
\hline
\end{tabular}

These results could be compared positively to the software calculations.

Once they have identified the bus involved in the cascade of overload that induces blackout presented at Figure 11, we opted to act in the first phase on the reactance of the critical lines between 22-8 and 22-19 by integrating a series FACTS in order to increase the static stability of the line and then we inserted a capacitor battery so as to raise the level of voltage at critical nodes. 
Mr. N. Belaguide et al. / International Journal of Computer Networks and Communications Security, 1 (6), November 2013

Simulation results are presented after integration at Figure 12.

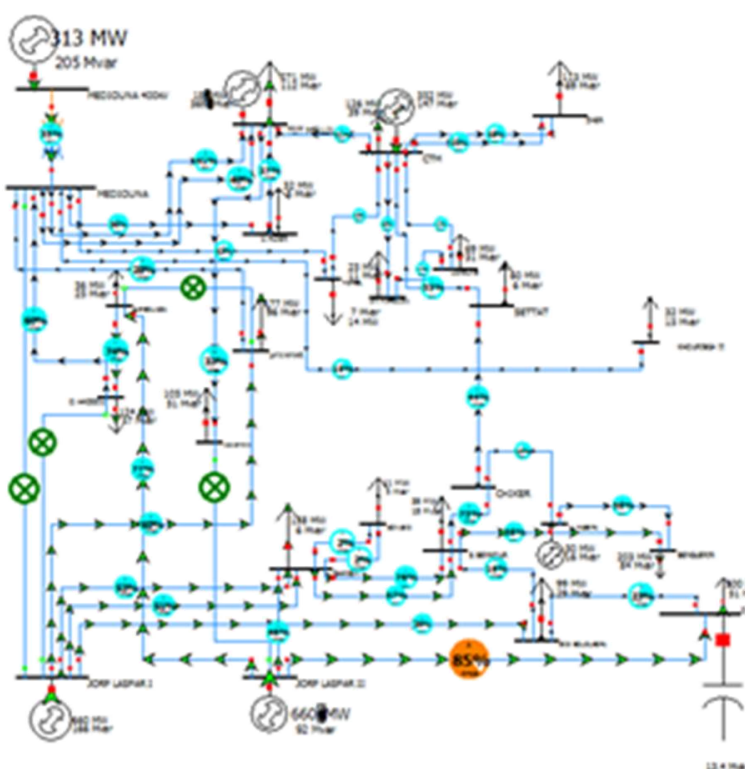

Fig. 12. Simulation after integration FACT
We note that this correction has allowed us to deal with a situation of BLACKOUT by action on the topology of the network and to improve network performance as shown in Table 2.

\section{Synthesis \& Openings}

The results obtained have helped us appreciate the foundation of the approach adopted, in the later stages we complete the development of the decision help algorithm aroused and we will extend the analysis to other dimensions.

\section{ACKNOWLEDGMENTS}

Our deep gratitude goes to the research team Energy and Power Systems for their support. The Directors of System Operator of ONEE for their cooperation

Table 2 : Results of POWER FLOW using MATLAB

Befor

e
After

Voltage of critical lines
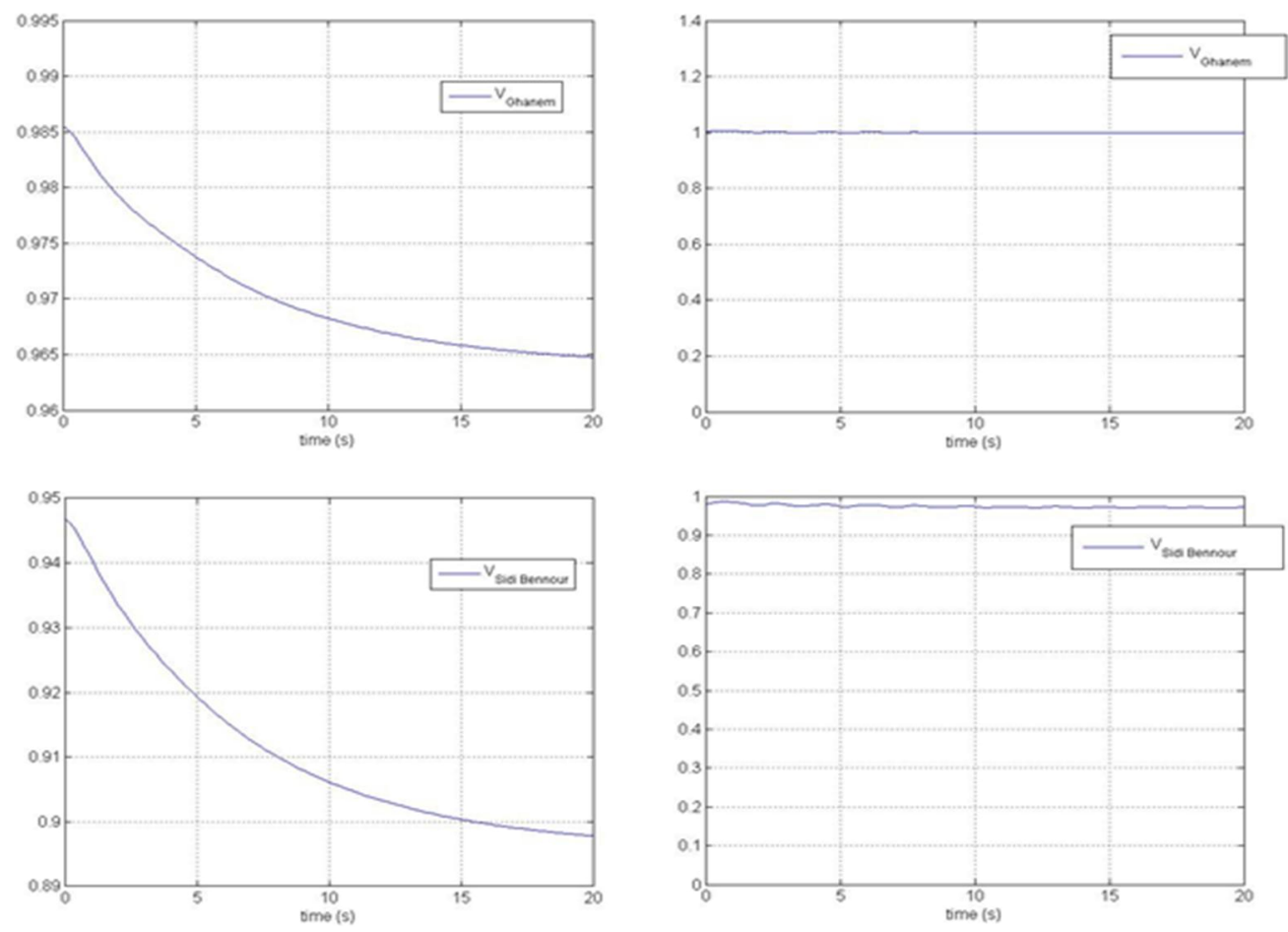

Table 2 : Results of POWER FLOW using MATLAB 


\section{REFERENCES}

[1] Najd BELAGUIDE, Abdellah SAAD, The development of a new concept of coordinated regulation of the electrical parameters of the network based on FACTS technology, Electrical Engineering Electronic Journal EEEJ, 2013.

[2] B. M. Weedy, B. J. Cory, Electric Power Systems, British library Fourth Edition, (2004) 95-157.

[3] Kundur P., Power System Stability and Control, McGraw - Hill, New York (1994) 699-1099.

[4] John J. Grainger, Wiliam D. Stevenson, Power System Analysis, McGraw - Hill, New York (1994) 193-233.

[5] Dang Toan NGUYEN, Contribution to the analysis and prevention of blackouts in power grids, $\mathrm{PhD}$ Polytechnic Institute of Grenoble (2008) 5-13.

[6] Wei LU, The optimal load shedding for the prevention of major blackouts, $\mathrm{PhD}$ Polytechnic Institute of Grenoble in 2009.

[7] A.A. Alabduljabbara, J.V. Milanovi'cb, Assessment of techno-economic contribution of FACTS devices to power system operation, Electric Power Systems Research, 2010.

[8] Yufeng GUO, Daren Yu, The influence of interconnection of electric power systems on load characteristic and frequency regulation, Electric Power Systems Research, 2003.

[9] E. Acha, V.G. Agelidis, O. Anaya-Lara and T.G.E miller, Power Electronic Control in Electrical Systems, Great Britain-MPG Books Ltd, (2002) 8.

[10] Michel CRAPPE, Electric Power Systems, John Wiley \& Sons, Inc, USA (2008) 18-35.

[11]M. Saravanan, S. Mary Raja Slochanal, P. Venkatesh and J. Prince Stephen Abraham, Application of particle swarm optimization technique for optimal location of FACTS devices considering cost of installation and system loadability, Electric Power Systems Research, 2006.

[12] Ghadir RADMAN, Reshma S. Raje, Dynamic model for power systems with multiple FACTS controllers, Electric Power Systems Research, 2007.

[13] Belkacem MAHDAD, a, T. Bouktir b, K. Srairi $\mathrm{a}$ and M. EL Benbouzid, Dynamic strategy based fast decomposed GA coordinated with FACTS devices to enhance the optimal power flow, Energy Conversion and Management, 2010 .
[14] Salman Hameed, Biswarup Das and Vinay Pant, A self-tuning fuzzy PI controller for TCSC to improve power system stability, Electric Power Systems Research, 2008.

[15]M.H. Haque, Damping improvement by FACTS devices: A comparison between STATCOM and SSSC, Electric Power Systems Research, 2006. 